\title{
Managerial multiple objective optimization
}

\author{
Ralph E. Steuer ${ }^{1} \cdot$ José Rui Figueira $^{2} \cdot$ Hatem $_{\text {Masri }}^{3}$ \\ Published online: 25 June 2018 \\ ○) Springer Science+Business Media, LLC, part of Springer Nature 2018
}

This special issue comprises extended versions of selected papers presented during the 11th International Conference on Multiple Objective Programming and Goal Programming (MOPGP'15), held from 13 to 15 December 2015 in Tlemcen, Algeria, as well as papers that were not presented during the conference. The MOPGP is a scientific forum within which researchers and practitioners can meet and learn from each other about recent developments in multi-objective decision making and multi-criteria decision aid and their applications. MOPGP aims to disseminate this knowledge, encouraging interest and training doctorate candidates in this field of study and promoting rigorous use of multi-objective decision making and multi-criteria decision aid tools in solving real decision-making situations.

The topics discussed in this special issue include, but are not limited to, all areas of multiple objective optimization (MOP), in particular those addressing managerial problems:

- theories and applications of MOP/GP

- fuzzy sets, soft computing and MOP/GP

- neural networks, meta-heuristics and MOP/GP

- interactive MOP/GP methods

- evolutionary MOP

- discrete and combinatorial MOP/GP

- stochastic MOP/GP

- fuzzy MOP/GP

- dynamic MOP/GP

The guest editors would like to thank Professor Endre Boros, Editor-in-Chief of the journal, for offering us the opportunity to edit this special issue and we look forward to more interesting

Ralph E. Steuer

rsteuer@uga.edu

José Rui Figueira

figueira@tecnico.ulisboa.pt

Hatem Masri

hmasri@uob.edu.bh

1 Department of Finance, University of Georgia, Athens, USA

2 CEG-IST, Instituto Superior Técnico, Universidade de Lisboa, Lisbon, Portugal

3 College of Business Administration, University of Bahrain, Zallaq, Kingdom of Bahrain 
applications and research activity in the field of multiple objective programming and goal programming.

The Guest Editors:

Ralph E. Steuer

José Rui Figueira

Hatem Masri 